\title{
Utilizing Occupancy Models and Platforms-of-Opportunity to Assess Area Use of Mother-Calf Humpback Whales
}

\author{
J. J. Currie*, S. H. Stack, J. A. McCordic, J. Roberts \\ Pacific Whale Foundation, Wailuku, Maui, USA \\ Email: *research@pacificwhale.org
}

How to cite this paper: Currie, J.J., Stack, S.H., McCordic, J.A. and Roberts, J. (2018) Utilizing Occupancy Models and Platforms-of-Opportunity to Assess Area Use of Mother-Calf Humpback Whales. Open Journal of Marine Science, 8, 276-292. https://doi.org/10.4236/ojms.2018.82014

Received: February 16, 2018

Accepted: April 15, 2018

Published: April 18, 2018

Copyright (@) 2018 by authors and Scientific Research Publishing Inc. This work is licensed under the Creative Commons Attribution International License (CC BY 4.0).

http://creativecommons.org/licenses/by/4.0/

\section{c) (i) Open Access}

\begin{abstract}
The Hawaiian Islands, and particularly the Maui 4-island region, are a critical breeding and calving habitat for humpback whales (Megaptera novaeangliae) belonging to the Hawaii distinct population segment. Our aims were to test the use of platforms-of-opportunity to determine trends in mother-calf pod use of the region and to present opportunistic platforms as an alternative method of long-term, cross-seasonal monitoring. Data were collected from whale watching vessels over a 4-year period and analyzed using occupancy models to determine the probability of habitat use of pods with calves and pods without calves within the study area. Detection probability was influenced by survey effort and month for all pod types with detection of adult only pods further influenced by year. Pods with a calf showed a preference for shallow $(<100$ meters) low latitude waters $\left(<20.7^{\circ} \mathrm{N}\right)$, while pods without a calf preferred deeper waters ( $>75$ meters). Results presented here align with previous work, both in Hawaii and in other breeding grounds, which show a distinct segregation of mothers with a calf from other age-classes of humpback whales. The need for long-term continuous monitoring of cetacean populations is crucial to ensure species conservation. Data collected aboard platforms-of-opportunity, as presented here, provide important insight on humpback whale spatial and temporal distribution, which are essential for species protection and management.
\end{abstract}

\section{Keywords}

Humpback Whale, Occupancy Model, Platform of Opportunity, Whale and Dolphin Tracker, Area Use

\section{Introduction}

For the humpback whale (Megaptera novaeangliae), mother-calf associations are 
considered the strongest bond within an otherwise solitary species, and maintenance of this association is crucial to calf survival and eventual recruitment to the population [1] [2]. As such, understanding how and when mother-calf humpback whale pods use a specific area is important for the ecology of the species as well as its conservation and management, particularly for the Hawaiian population segment which was removed from the Endangered Species Act in 2016 [3]. Winter aggregations of humpback whales in Hawaiian waters belong to the Hawaii distinct population segment that utilize the main Hawaiian Islands as breeding and calving grounds and constitutes a significant portion: 10,000 [4] of the global population: 90,000 [5]. The highest densities of Hawaiian humpbacks occur within the Maui 4-island region [6] [7], consisting of Maui, Lana'i, Moloka'i, and Kaho'olawe. Spatial segregation of mother-calf pods within the Hawaiian breeding grounds has been observed (e.g., [8] [9] [10] with the Maui 4 -island region being the preferred habitat for mother-calf pods in this population [11] [12]).

Research on humpback whales in Brazil, Madagascar, Ecuador, and Costa Rica found that mother-calf pairs used shallower waters than groups without calves [10] [13] [14] [15]. Mother-calf pods may prefer shallower waters to avoid energetically costly situations such as aggressive attention from male suitors, rough waters that complicate nursing, or competition groups which may put the calf in danger [9] [10] [13] [14] [15] [16]. Observations of mother-calf pairs in Hawaii have reported similar findings across all islands. Pods containing mothers and calves near the island of Hawaii were observed in waters significantly shallower than groups of one or two adults [9]. Similarly [17] observed pods with a calf in shallower waters than other pod types observed on the north shore of Kaua'i.

Based on observations of pods with calves in the deeper waters of the Au'au channel between the islands of Maui and Lana'i, It has been suggested females with calves avoid the shallowest areas within 2 kilometers of the coastline [18]. Although this pattern contrasts other studies of mother-calf habitat preference for shallow waters, limitations were expressed by authors including a short survey season and timing of the study [18], potentially contributing to the contradicting results from other studies in the Hawaiian Islands and around the world [9] [10] [13] [14] [15] [16]. Observed variation in mother-calf habitat preference among breeding areas could be caused by differences in behavioral context, anthropogenic stress, or sampling methodologies [18].

Knowledge of mother-calf distribution throughout the Maui 4-island region could inform assessment of restrictions, including but not limited to vessel speed and area use, that may be placed to reduce animal disturbance and harm. This study compares the spatial distribution of humpback whale pods with and without calves over a 4-year period throughout the winter breeding season (December to April). We present on the analysis of humpback whale sighting data collected from platforms-of-opportunity to relate humpback whale pres- 
ence/absence to environmental characteristics and time of year in driving the observed distribution within the Maui 4-island region, utilizing occupancy modelling techniques [19] [20] [21]. This study, besides furthering the understanding of humpback whale distributions, presents opportunistic surveys as an effective method of continuous population monitoring, aiding in conservation efforts and species management.

\section{Materials and Methods}

\subsection{Study Area and Sampling Units}

The Maui 4-island region, which extends from $21^{\circ} 0^{\prime} \mathrm{N}$ to $21^{\circ} 35^{\prime} \mathrm{N}$ and $156^{\circ} 50^{\prime} \mathrm{W}$ to $156^{\circ} 25^{\prime} \mathrm{W}$, is semi-enclosed by the islands of Maui, Moloka'i, Lana'i, and Kaho'olawe and located within the Hawaiian Islands Humpback Whale National Marine Sanctuary. The water depths within this area range from $1-270 \mathrm{~m}$, and the bottom topography consists of drowned reef features and sandy, flat concentric basins [22].

The study area was divided into $1 \mathrm{~km} \mathrm{x} 1 \mathrm{~km}$ grid cells that covered $654 \mathrm{~km}^{2}$ (Figure 1). The majority (56\%) of water depth in the area ranged between 50 and $120 \mathrm{~m}$, with sea surface temperature remaining fairly constant throughout the season at $25^{\circ} \mathrm{C}-26^{\circ} \mathrm{C}$.

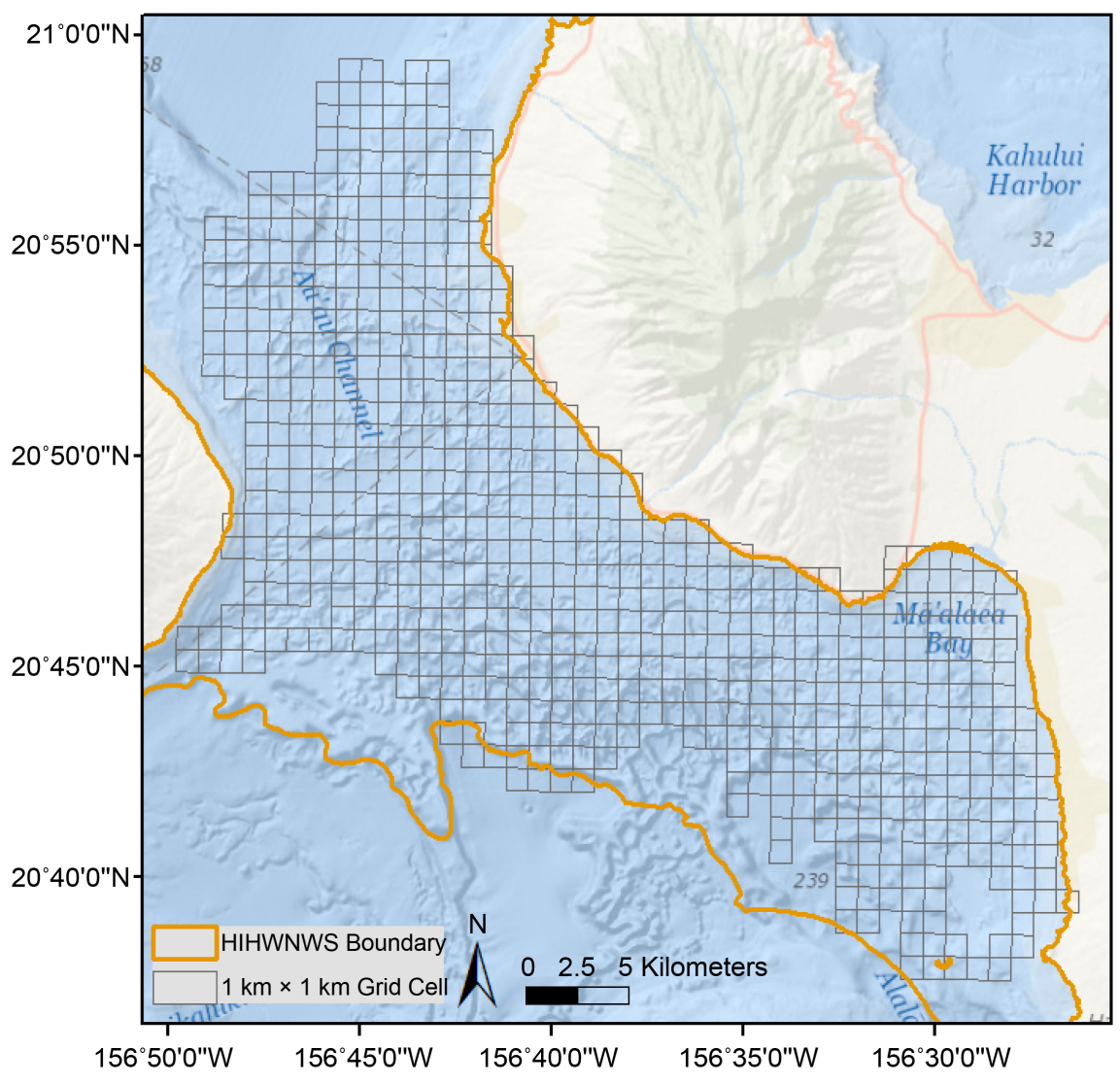

Figure 1. Map of study area showing bathymetry and $1 \mathrm{~km} \times 1 \mathrm{~km}$ grid cells sampled from December 1, 2013 to April 30, 2017. 


\subsection{Data Collection}

Humpback whale sighting data were collected from multiple whalewatching trips departing from both Ma'alaea and Lahaina Harbors daily between December 1, 2013 and April 30, 2017. Each whalewatching trip lasted 2 hours and followed a non-systematic survey design. Vessel speeds did not exceed 15 knots and whalewatches were conducted in Beaufort sea states of 6 or less.

Scanning for whales was completed by two trained observers and began once boats departed the harbor. Scanning was conducted by naked eye and with binoculars looking for visual cues of humpback whale presence. Survey effort (GPS track) and sighting details were recorded using the Whale and Dolphin Tracker (WDT) application [23]. When a whale was sighted, the vessel approached the pod to a distance $\geq 91$ meters (100 yards), in accordance with federal regulations. Upon approach and subsequent observation, information on group size, composition, and behavior were recorded. To ensure accurate group composition and size estimates, only sightings where group composition could be confirmed were included in subsequent analysis. Encounter location (latitude and longitude) was recorded using WDT when the vessel was $\leq 150$ meters from the focal pod, as this distance provided sufficient geospatial resolution for the subsequent analysis and remained outside the 100 yard approach limit.

\subsection{Data Analysis}

Whalewatches are non-systematic surveys that do not incorporate transect lines, equal coverage of the sampling area, or distance sampling techniques. As such, a full distance sampling analysis generally utilized for cetacean surveys is not appropriate for this type of dataset. Instead, the authors utilize occupancy modelling which allows for the correction of biases inherent in opportunistic data collection, without requiring distance sampling techniques. Occupancy modelling relies on two components: site occupancy $\left(\psi_{i}\right)$, which is the probability that a species occupies the sampling site $i$, and is modelled as a function of site-specific covariates; and detectability $\left(p_{i j}\right)$, which is the probability that a species is detected during survey $j$ at site $i$, and is modelled as a function of either site-specific or survey-specific covariates. Each are estimated using the logit-link function [24] [25]:

$$
\begin{aligned}
& \text { Occupancy }=\operatorname{logit}\left(\psi_{i}\right)=\ln \left(\frac{\psi_{i}}{1-\psi_{i}}\right)=\alpha_{0}+\alpha_{1} x_{1, i}+\alpha_{2} x_{2, i} \\
& \text { Detection Probability }=\operatorname{logit}\left(p_{i j}\right)=\ln \left(\frac{p_{i, j}}{1-p i, j}\right) \\
& =\beta_{0}+\beta_{1} x_{1, i}+\beta_{2} x_{2, i}+\beta_{3} y_{1, i j}+\beta_{4} y_{2, i j}
\end{aligned}
$$

where $\ln$ is the natural logarithm, $x$ represents site-specific covariates, $y$ represents survey-specific covariates, $\alpha$ and $\beta$ are the estimated regression coefficients.

Although rarely used for cetacean surveys, occupancy models, with a slight 
adjustment in interpretation, can be used as a viable option for analyzing habitat preferences of humpback whales using sighting data collected on WDT. The adjustments to parameter interpretation and details on how assumptions for occupancy modelling were met in the context of this dataset are detailed below.

Similar to the approach presented in previous studies [25], this study examined humpback whale use as opposed to occupancy, and the assumption of geographic closure is not met. To account for this we interpret model output as the probability of humpback whale use, as opposed to occupancy, which in conjunction with the whales' ability to move in and out of the survey sites allows us to relax the assumption of geographic closure [24].

The likelihood of false identifications of humpback whales is minimal given the size and nature of humpback whales. Additionally, there are no other mysticete whales that are commonly found in the Maui 4-island region. To ensure that the survey adhered to the assumption of no false identifications, only sightings where the whalewatching vessel approached the pod and positively confirmed the species as humpback whales were used.

To ensure detection of a humpback whale at one site was independent of detection at another, the final data were randomly subset to include only a single whalewatch trip from each harbor for each survey day. This subset was then utilized in subsequent analysis and the distance between the harbors ensured a humpback whale was not detected at multiple sites during a survey day.

To ensure there was no unmodelled heterogeneity, site and survey covariates known to impact humpback whale detection and occupancy were recorded in the field or calculated post survey and detailed below:

\subsection{Site Covariates}

Each site was characterized by the following variables: water depth, slope, distance to shore, latitude, longitude, and relative bottom terrain ruggedness. Mean site water depth was expressed in meters taken from Hawaii Mapping Research Group (HMRG) Bathymetry Synthesis data set (Resolution: $50 \mathrm{~m}$ ) [26]. The mean slope at each site was expressed in degrees $\left(0^{\circ}-90^{\circ}\right)$ and determined using the slope tool in ArcMap [27]. Distance from shore was expressed as positive value in kilometers and determined using the near tool in ArcMap [27] to measure the distance from the center of each site to the nearest shoreline. Relative bottom terrain ruggedness [28] was calculated from bathymetry dataset [26] in ArcMap [27]. Site covariates were tested for pairwise correlations using the stats package in $\mathrm{R}$ [29]. To account for non-normality in site covariates, the Spearman correlation coefficient $\left(r_{s}\right)$ was used to assess correlations. If site covariates were highly correlated $\left(r_{s} \geq 0.7\right)$ [30], the most biologically relevant variable was retained.

\subsection{Survey Covariates}

Potential effects on detection included month within the survey season (Janu- 
ary-April), survey effort/grid cell expressed as kilometers, and year. In this study, the effects of pod size and whale behavior were not accounted for since these variables could not readily be incorporated into the model.

\subsection{Data Preparation}

The data set was divided into two categories and detection histories created for each: one for pods without a calf present and one for pods with a calf present for each month during whale season (December, January, February, March, and April) from 2013-2017. For adult pods, a grid cell was given a "1" for detection when the cell was only occupied by pods that did not contain calves throughout the survey period. Sites that were sampled, but did not detect any pods, or detected pods with calves were given a "0". For calf pods, a grid cell was given a "1" for detection when the cell was occupied at least once by pod(s) that contained a calf throughout the survey period. A " 0 " was assigned to sites that were sampled, but did not detect any pods, or detected pods that did not contain a calf.

Data were analyzed using the unmarked package [31] in $\mathrm{R}$ to fit dynamic occupancy models [32] to humpback whale presence absence data. Two models were developed, one for pods without a calf present and one for pods with calves present (here after referred to as "adult model" and "calf model" respectively). In these analyses, data on "pod" presence and absence within a particular site are used to draw conclusions on humpback whale habitat preference for pods with and without a calf. The final adult and calf model predictions should be interpreted as the probability of humpback whale adult pod and humpback whale calf pod use within the Maui 4-island region.

Akaike Information Criterion (AIC) values [33] of fitted models were used to assess candidate models and obtained according to the following formula:

$$
\mathrm{AIC}=-2 L+2 K
$$

where $L$ is the maximum $\log$-likelihood and $K$ represents the number of parameters in the fitted model. The change in AIC ( $\triangle \mathrm{AIC})$ was used to rank the candidate models and calculated using the following formula:

$$
\triangle \mathrm{AIC}=\mathrm{AIC}-\mathrm{AIC}_{\text {bestmodel }}
$$

The most parsimonious model, having the lowest AIC value, was selected as the best fit model. Initial models included all sampling and site covariates, which were further subset and in different combinations based on model AIC values and weights $\left(\mathrm{AIC}_{\mathrm{wt}}\right)$. $\mathrm{AIC}_{\mathrm{wt}}$ was calculated for model $m$, using the following formula:

$$
\left(\mathrm{AIC}_{\mathrm{wt}}\right)_{m}=\frac{\exp \left(-\frac{1}{2} \Delta_{m} \mathrm{AIC}\right)}{\sum_{k=1}^{K}-\frac{1}{2} \Delta_{k}(\mathrm{AIC})}
$$

To test model fit, the MacKenzie and Bailey Goodness-of-fit Test in $\mathrm{R}$ (mb.gof.test) using 10,000 bootstrap samples was run and c-hat calculated to 
check for over dispersion [32] [34].

\section{Results}

From December 2013 to April 2017 a total of 1089 whalewatching trips were completed accounting 13,878 nautical miles of survey effort. During this time period humpback whale pods without calves were detected 786 times in 309 of the 654 grid cells sampled, while pods with calves were detected 682 times in 256 of the 654 grid cells sampled. Over the 4 months of observation, detections were highest in January for pods without calves $(n=250)$ and March for pods with calves $(n=201)$ (Table 1$)$.

The most supported model of detection probability for the calf model and the adult model both included effects of survey effort and month (Table 2 and Table 3). Including a yearly effect in detection probability significantly improved model fit for the adult model only (Table 2 and Table 3 ).

The probability of detection for both the adult model and calf model increased with effort (Table 4). Progression from early whale season (December) to late whale season (April) saw an increase in probability of detection for the calf model and a decrease in probability of detection for the adult model (Table 4; Figure 2):

Table 1. Detection histories of humpback whale pods with and without calves sighted within a $1 \mathrm{~km} \times 1 \mathrm{~km}$ site in the Maui 4-island region, Hawaii from December 2013 to January 2017.

\begin{tabular}{ccccccccc}
\hline & \multicolumn{2}{c}{$2013-2014$} & \multicolumn{2}{c}{$2014-2015$} & \multicolumn{2}{c}{$2015-2016$} & \multicolumn{2}{c}{$2016-2017$} \\
\cline { 2 - 8 } & Adult & Calf & Adult & Calf & Adult & Calf & Adult & Calf \\
\hline December & 65 & 14 & 32 & 15 & 49 & 8 & 81 & 7 \\
January & 49 & 37 & 34 & 34 & 71 & 28 & 96 & 26 \\
February & 19 & 50 & 21 & 35 & 37 & 47 & 48 & 48 \\
March & 21 & 48 & 26 & 46 & 29 & 55 & 44 & 52 \\
April & 8 & 43 & 11 & 20 & 23 & 37 & 22 & 42 \\
\hline
\end{tabular}

Table 2. Model selection results of detection probability for humpback whale pods without calves using the Maui 4-island region from December 2013 to January 2017.

\begin{tabular}{ccccc}
\hline Model & $K$ & AIC & $\Delta \mathrm{AIC}$ & $\mathrm{AIC}_{\mathrm{wt}}$ \\
\hline$p$ (month + effort + year $)$ & 9 & 3817.75 & 0.00 & 1.00 \\
$p$ (month + effort $)$ & 6 & 3845.08 & 27.33 & 0.00 \\
$p$ (effort + year $)$ & 8 & 3877.02 & 59.27 & 0.00 \\
$p$ (month + year $)$ & 8 & 3899.98 & 82.22 & 0.00 \\
$p$ (effort) & 5 & 3903.50 & 85.75 & 0.00 \\
$p$ (month) & 5 & 3931.68 & 113.93 & 0.00 \\
$p($ year $)$ & 7 & 3950.48 & 132.72 & 0.00 \\
$p()$. & 4 & 3980.98 & 163.23 & 0.00
\end{tabular}

Note: Table values represent model AIC, the change in AIC for the best model $(\triangle \mathrm{AIC})$, the Akaike weights $\left(\mathrm{AIC}_{\mathrm{wt}}\right)$, and number of parameters $(\mathrm{K})$. 
Table 3. Model selection results of detection probability for humpback whale pods with calves using the Maui 4-island region from December 2013 to January 2017.

\begin{tabular}{ccccc}
\hline Model & $K$ & $\mathrm{AIC}$ & $\Delta \mathrm{AIC}$ & $\mathrm{AIC}_{\mathrm{wt}}$ \\
\hline$p$ (month + effort) & 6 & 3300.56 & 0.00 & 0.86 \\
$p$ (month + effort + year) & 9 & 3304.10 & 3.55 & 0.14 \\
$p$ (effort) & 5 & 3409.91 & 109.35 & 0.00 \\
$p$ (effort + year) & 8 & 3413.84 & 113.29 & 0.00 \\
$p$ (month + year) & 8 & 3501.73 & 201.17 & 0.00 \\
$p$ (month) & 5 & 3503.15 & 202.59 & 0.00 \\
$p($ year $)$ & 7 & 3614.31 & 313.75 & 0.00 \\
$p()$. & 4 & 3621.90 & 321.34 & 0.00 \\
\hline
\end{tabular}

Note: Table values represent model AIC, the change in AIC for the best model $(\triangle \mathrm{AIC})$, the Akaike weights $\left(\mathrm{AIC}_{\mathrm{wt}}\right)$, and number of parameters $(K)$.

Table 4. Untransformed estimates and standard errors of detection covariates for constant habitat model for humpback whale pods with and without calves in the Maui 4-island region, Hawaii.

\begin{tabular}{cccccc}
\hline Model & $\hat{\beta}_{\text {effort }}$ & $\hat{\beta}_{\text {month }}$ & $\hat{\beta}_{\text {year14-15 }}$ & $\hat{\beta}_{\text {year15-16 }}$ & $\hat{\beta}_{\text {year 16-17 }}$ \\
\hline \multirow{2}{*}{ Adult model } & $\begin{array}{c}0.073^{* * *} \\
(0.008)\end{array}$ & $\begin{array}{c}-0.252^{* * *} \\
(0.033)\end{array}$ & $-0.357^{*}$ & 0.040 & $0.391^{*}$ \\
& $0.168)$ & $(0.175)$ & $(0.179)$ \\
Calf model & $\begin{array}{c}0.092^{* * *} \\
(0.007)\end{array}$ & $\begin{array}{c}0.349^{* * *} \\
(0.034)\end{array}$ & & & \\
\hline
\end{tabular}

Note: ${ }^{*}$ indicates the following significance levels: ${ }^{* * *}(0.0001-0.001),{ }^{* *}(0.001-0.01),{ }^{*}(0.01-0.05)$.

$$
\begin{gathered}
\text { Adultp }_{i j}=-1.533+0.119_{\text {depth }}+0.073_{\text {effort }}-0.252_{\text {month }} \\
-0.357_{\text {year14-15 }}+0.040_{\text {year15-16 }}+0.391_{\text {year16-17 }} \\
\text { Calfp }_{i j}=-3.256-0.081_{\text {depth }}-14.342_{\text {latitude }}+0.092_{\text {effort }}+0.349_{\text {month }}
\end{gathered}
$$

Correlation analysis found depth and distance from shore as well as latitude and longitude to be correlated, with values of 0.76 and 0.73 respectively. Between depth and distance from shore, depth was retained as the most biologically relevant parameter given that there is no clear on-shore off-shore gradient, and the surrounding 4 islands can confound this measurement with no easily explained proxy for distance from shore relating to humpback whale use within this particular study area. Furthermore, the bathymetry within the Maui 4-island region is complex with areas or large relatively uniform depth as well as steep gradients and depth contours which may impact how adult and calf humpback whale pods utilize the region. Latitude was favored over longitude, given the larger north-south gradient within the study area. Once correlated variables were removed, the following site covariates remained: depth, slope, roughness, and latitude. Depth ranked at the top for both adult and calf models (Table 5 and Table 6). Including only a depth covariate resulted in the best fitting model for pods without calves (Table 5).

The top ranked model for pods with calves included site covariates for depth, 


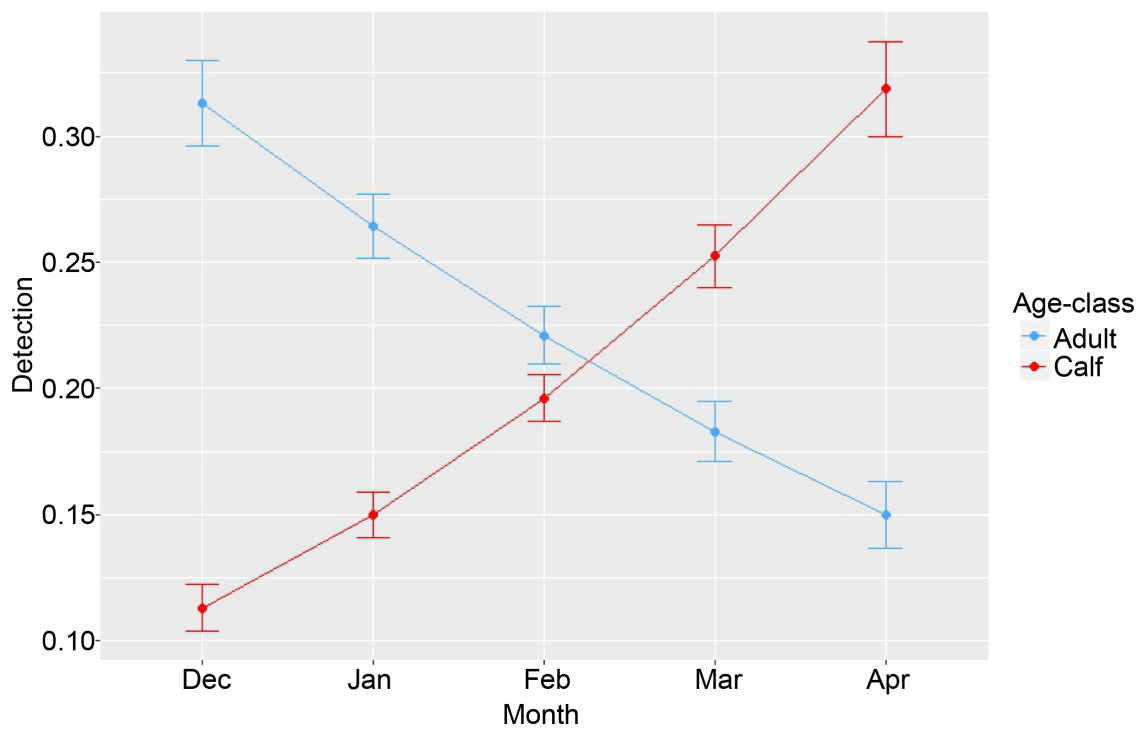

Figure 2. Relationship of predicated detection probability with month from the adult (blue) and calf (red) models for humpback whales detected in the Maui 4-island. The error bars represent the $95 \%$ confidence interval.

Table 5. AIC values for multi-season occupancy models describing the influence of environmental factors on the occurrence of humpback whale pods without calves in the Maui 4-island region from December 2013 to January 2017.

\begin{tabular}{ccccc}
\hline Adult Models & $K$ & AIC & $\Delta$ AIC & AIC $_{\mathrm{wt}}$ \\
\hline$p$ (month + effort + year $), \psi($ depth $)$ & 10 & 3776.25 & 0.00 & 1.00 \\
$p$ (month + effort + year $), \psi($ depth + latitude $)$ & 8 & 3815.16 & 38.92 & 0.00 \\
$p$ (month + effort + year $), \psi($ depth + latitude + slope $)$ & 9 & 3816.54 & 40.30 & 0.00 \\
$p(),. \psi()$ & 9 & 3817.75 & 41.51 & 0.00 \\
$p($ month + effort + year $), \psi($ depth + slope $)$ & 8 & 3818.52 & 42.27 & 0.00 \\
$p$ (month + effort + year $), \psi($ slope $)$ & 10 & 3819.14 & 42.89 & 0.00 \\
$p($ month + effort + year $), \psi($ roughness $)$ & 10 & 3819.53 & 43.28 & 0.00 \\
$p($ month + effort + year $), \psi($ latitude $)$ & 10 & 3819.76 & 43.52 & 0.00 \\
$p($ month + effort + year $), \psi($ slope + latitude $)$ & 8 & 3848.71 & 72.47 & 0.00 \\
\hline
\end{tabular}

slope, and latitude (Table 6). However, including slope only marginally reduced the AIC value $(\triangle \mathrm{AIC}=0.43)$. To ensure the most parsimonious model was used, the final model selected included covariates for depth and latitude only.

There was no evidence of over dispersion for the best adult and calf models ( $\hat{c}<$ 1). The Mackenzie-Bailey (2004) chi-square test found both models predicted the data well (calf model p-value $=0.58$; adult model $\mathrm{p}$-value $=0.48$ ).

Depth was the most important variable for determining humpback whale use, appearing in all of the top ranking models and being absent from the lowest ranking models (Table 5 and Table 6). Depth showed a significant positive relationship with humpback whale use for the adult model and a significant negative relationship with humpback whale use for the calf model (Table 7). 
Table 6. AIC values for multi-season occupancy models describing the influence of environmental factors on the occurrence of humpback whale pods with calves in the Maui 4-island region from December 2013 to January 2017.

\begin{tabular}{ccccc}
\hline Calf Models & $K$ & $\mathrm{AIC}$ & $\Delta \mathrm{AIC}$ & $\mathrm{AIC}_{\mathrm{wt}}$ \\
\hline$p($ month + effort $), \psi($ depth + slope + latitude $)$ & 9 & 3290.15 & 0.00 & 0.44 \\
$p$ (month + effort $), \psi($ depth + latitude $)$ & 8 & 3290.58 & 0.43 & 0.35 \\
$p$ (month + effort $), \psi($ depth $)$ & 7 & 3293.24 & 3.09 & 0.10 \\
$p$ (month + effort $), \psi($ depth $)$ & 7 & 3295.15 & 5.00 & 0.04 \\
$p$ (month + effort $), \psi($ slope + latitude $)$ & 8 & 3295.15 & 5.01 & 0.04 \\
$p($ month + effort $), \psi($ depth + slope $)$ & 8 & 3295.21 & 5.06 & 0.03 \\
$p($ month + effort $), \psi($ slope $)$ & 7 & 3300.14 & 9.99 & 0.00 \\
$p(),. \psi()$. & 6 & 3300.56 & 10.41 & 0.00 \\
$p($ month + effort $), \psi($ roughness $)$ & 7 & 3302.23 & 12.08 & 0.00 \\
\hline
\end{tabular}

Table 7. Untransformed estimates and standard errors of site covariates for the probability of humpback whale use, after accounting for imperfect detections, for pods with and without calves in the Maui 4-island region, Hawaii.

\begin{tabular}{ccc}
\hline Model & $\hat{\beta}_{\text {depth }}$ & $\hat{\beta}_{\text {latitude }}$ \\
\hline Adult model & $0.119^{* * *}(0.024)$ & \\
Calf model & $-0.081^{* *}(0.026)$ & $-14.342(9.26)$ \\
\hline
\end{tabular}

Note: ${ }^{*}$ indicates the following significance levels: ${ }^{* *}(0.0001-0.001),{ }^{* *}(0.001-0.01),{ }^{*}(0.01-0.05)$.

The probability of use increased with increasing depth for adult pods, with the highest probability occurring in waters with a depth of 75 meters or more (Figure 3):

$$
\text { Adult } \psi_{i}=-3.160+0.119_{\text {depth }}
$$

The reverse was observed for calf pods, with the probability of use remaining high at depths of $<100$ meters, after which the probability of use drops quickly (Figure 4). In addition to depth, calf pods were also influenced by latitude, with the probability of use remaining high at lower latitude $\left(<20.7^{\circ} \mathrm{N}\right)$ for calf pods, after which probability of use decreases (Figure 5):

$$
\text { Calf } \psi_{i}=305.867-0.081_{\text {depth }}-14.342_{\text {latitude }}
$$

The preference of shallow waters and low latitudes within the study area suggest calf pods may prefer Ma'alaea Bay over other areas of the Maui 4-island region.

The calf model predicted highest whale use in the shallow waters from the east coast of Lana'i, through the Au'au channel and along the southwest coast of Maui (Figure 6(a)). The adult model predicted highest whale use in deeper water off the west coast of Maui and in the center of the Maui 4-island Region (Figure 6(b)). There was minimal overlap between high use areas (probability of area use $>0.9$ ) of pods with calves and pods without calves, with each preferring different areas of the Maui 4-island region. Some overlap of predicted area use 


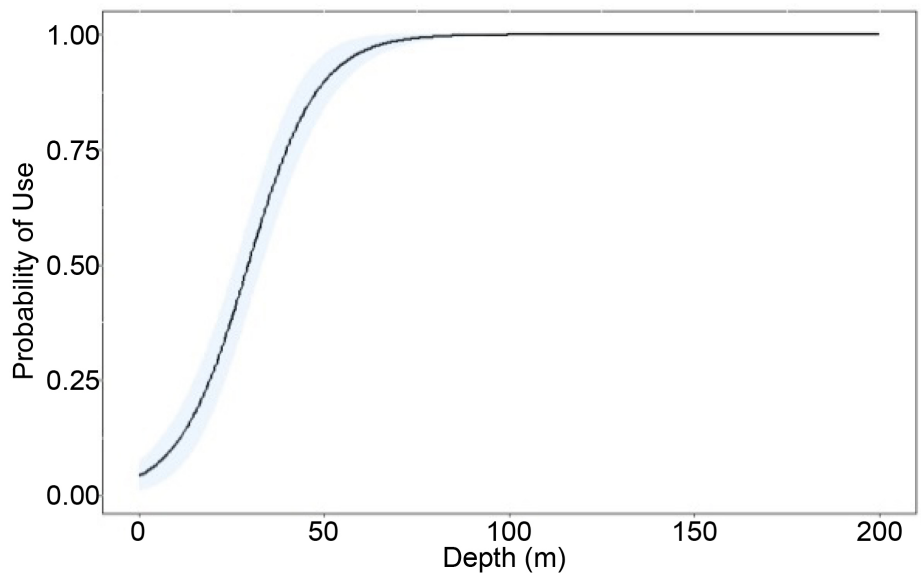

Figure 3. Relationship of probability of whale use with varying depth for humpback whale pods without calves predicted from the adult model. The blue band represents the $95 \%$ confidence interval.

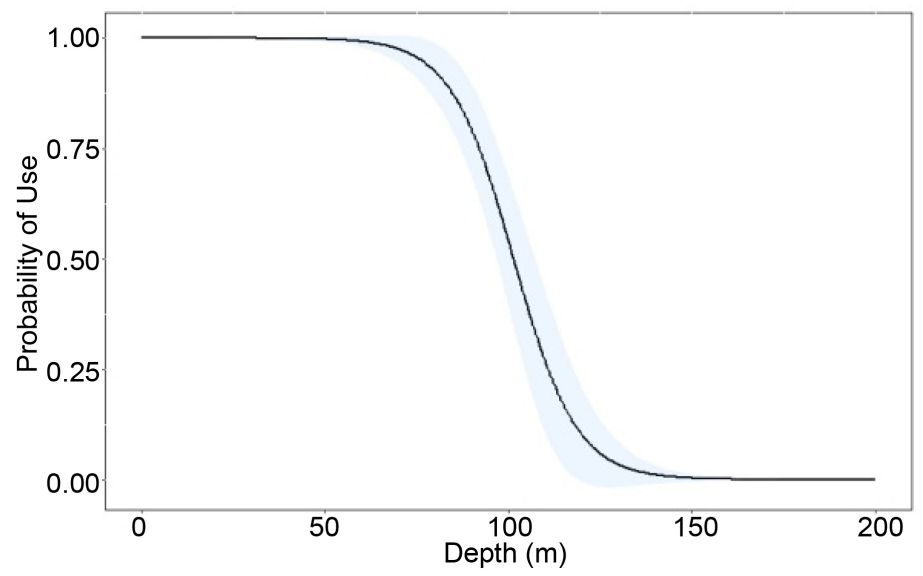

Figure 4. Relationship of probability of whale use with varying depth for humpback whale pods with calves predicted from the calf model. The blue band represents the $95 \%$ confidence interval.

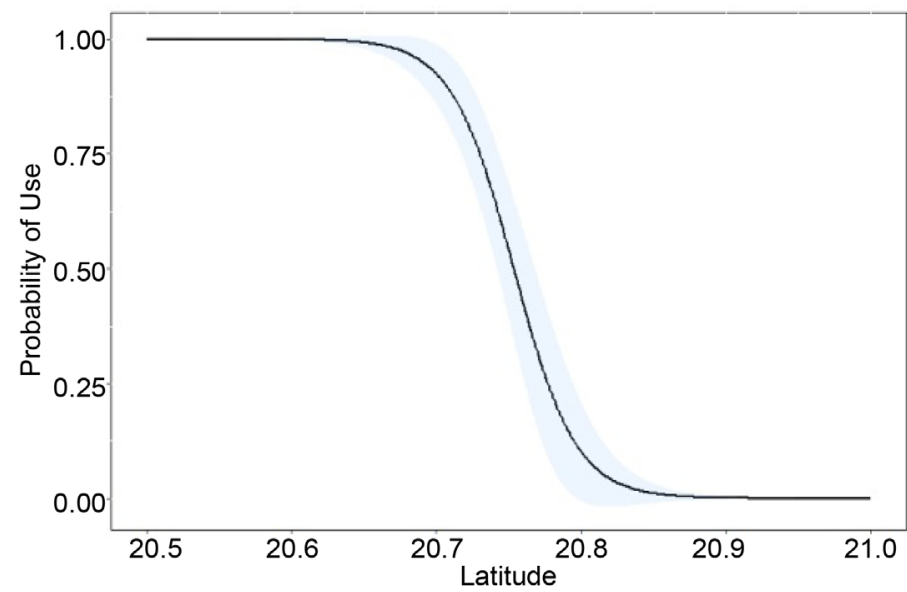

Figure 5. Relationship of probability of whale use with varying latitude for humpback whale pods with calves predicted from the calf model. The blue band represents the $95 \%$ confidence interval. 


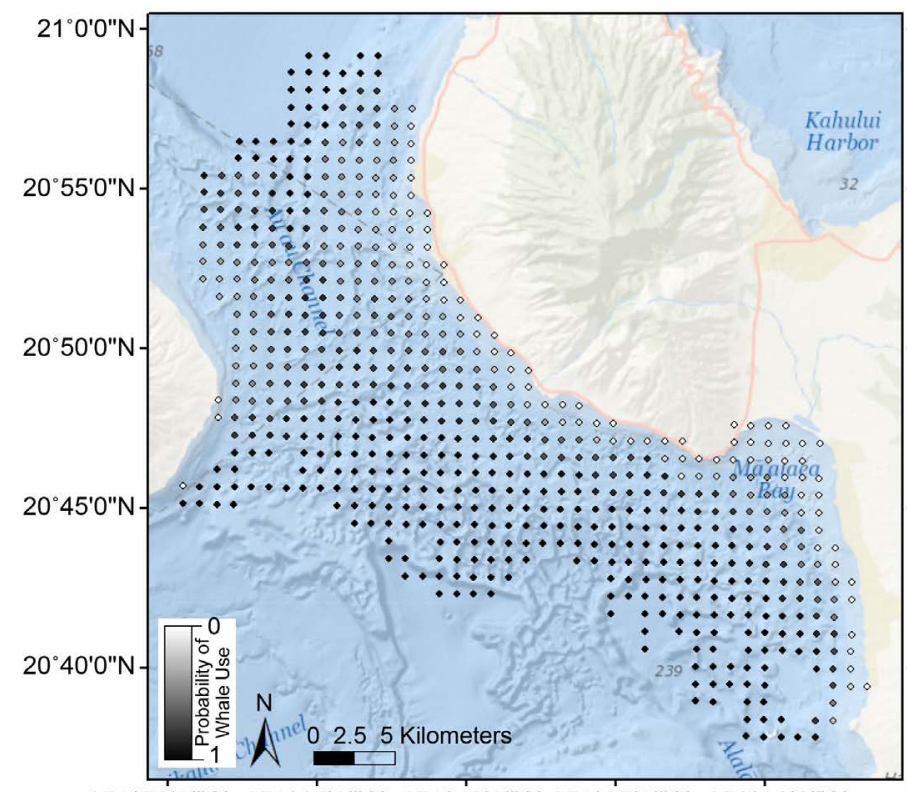

$156^{\circ} 50^{\prime} 0^{\prime \prime} \mathrm{W} 156^{\circ} 45^{\prime} 0^{\prime \prime} \mathrm{W} 156^{\circ} 40^{\prime} 0$

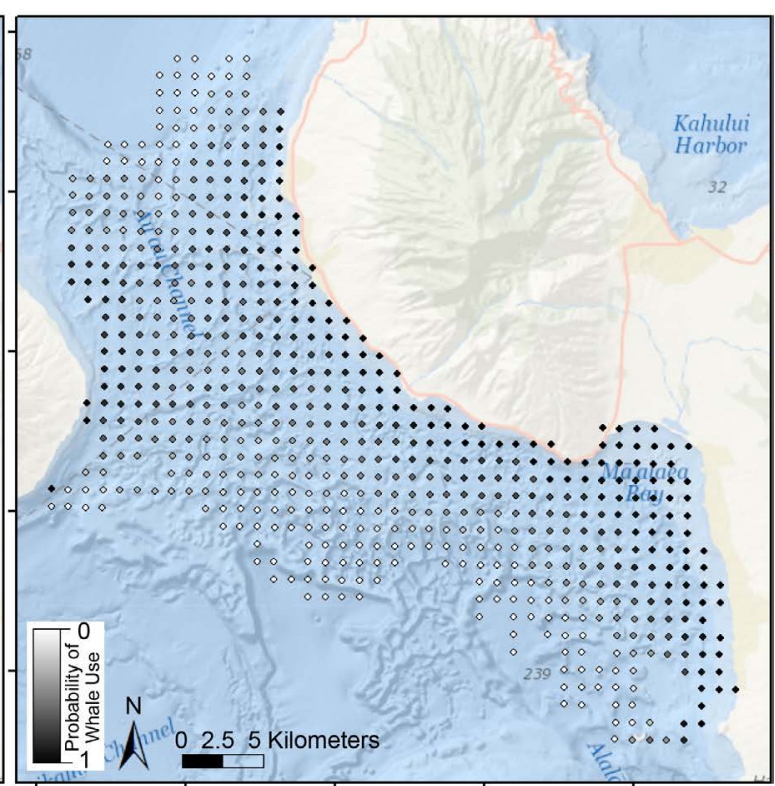

(b)

Figure 6. Predicted probability of whale use for pods without calves (a) and pods with calves (b). Note: Points represent centroid of predicted site $(1 \mathrm{~km} \times 1 \mathrm{~km})$ and were utilized to allow for visualization of varying use with bathymetry.

existed between calf and adult pods, with the most overlap occurring within the Au'au Channel between Maui and Lana'i (Figure 6(a) and Figure 6(b)).

\section{Discussion}

This study compares the spatial distribution of humpback whale pods with and without calves over a 4-year period throughout the winter breeding season (December to April). The Maui 4-island region is a critical breeding habitat for humpback whales belonging to the Central North Pacific stock. This study, besides furthering the understanding of humpback whale distribution and habitat use in this region, presents opportunistic surveys as an effective method of continuous population monitoring aiding in conservation efforts and species management.

\subsection{Depth and Latitude Effects}

The results from this study provide strong evidence that the typical patterns of distribution according to age-class and group composition that are seen in other humpback whale breeding areas are also evident in the Maui 4-island region. This study agrees with previous work, both in Hawaii and in other breeding grounds, that mother-calf humpback whale pods demonstrate a habitat preference for shallow, nearshore waters.

Our results show that there is an inverse relationship in the probability of area use between pods with a calf and pods without a calf present. Pods containing a calf were likely to be found in shallower waters, while pods containing no calves were likely to be found in deeper waters. The data collected had high geographic 
and temporal coverage, which lead to strong confidence in the predicted results.

The effect of latitude suggests that pods with a calf present were most likely to use the southern portion of the survey area, specifically areas to the south of Ma'alaea Bay. This southern area has similar depth characteristics as other habitat areas along the northwest coast of Maui but may represent a region which is more protected from rough weather and anthropogenic disturbances. Rough weather could include wind or swells that might complicate nursing or increase energetic demands of swimming [9] [35] [36]. Northeast trade winds dominate weather patterns in Maui and throughout the Main Hawaiian Islands [37], and a north-northwest swell is predominant during the winter months while the humpback whales utilize the Hawaiian Islands [38]. Within the Maui 4-island region, this southern area may represent one of the most protected habitats in terms of wind and swell due to its southeast location in the lee of Maui and Haleakala volcano. This observed trend may also represent an avoidance strategy of commercial shipping traffic, which generally use the larger channels (Au'au, Kealaikahiki, Alalakeiki) and bypass south Maui [39].

There are no long term studies examining the habitat preference of mother-calf pairs in Maui leeward waters. Previous studies have reported mother-calf pairs preferring nearshore waters [40], locations $<0.5 \mathrm{~km}$ of shoreline along west Maui [41], and shallower waters [16]. Previous research reported contradicting trends to previous studies [18]; however, that study was limited both geographically and temporally (examining only a portion of the Au'au Channel and only in March). Our model is strengthened by our large data set: four months (December to April) of daily whale sightings spread out over a large survey area. The model predicted pods containing a calf to occur just inside of the bathymetry gradient occurring in the Au'au Channel. This aligns with the finding that depth is a significant predictor for use of a grid cell by both pods with a calf and without a calf.

\subsection{Seasonal Effects}

Humpback whales tend to migrate based on age and sex classes [42], with sub-adults being first, then mature adults and mother-calf pairs being the final group to migrate [40] [43]. Similarly, the composition of pods sighted in this study varied by month. The predominant group type was non-calf pods in December and January, while those with calves were predominantly observed in February, March, and April. The continued long-term, cross-seasonal monitoring presented here will allow for the determination of trends and for monitoring of potential changes and seasonal shifts.

\subsection{Using Opportunistic Data}

The use of opportunistic data is becoming increasingly important as an inexpensive, accessible method of cetacean monitoring. WDT is no exception, having recorded over 35,000 georeferenced sightings of 11 different species at no addi- 
tional cost for survey effort. The ability to track large scale changes in marine environments can be aided by opportunistic data, such as those collected using WDT. However, it is important to note the use of opportunistic platforms can potentially introduce sources of variation and bias which need to be accounted for. Our occupancy models to predict humpback whale use from WDT data aligns with findings from previous research showing distinct area use of mother-calf pods within the Maui 4-island region [18] [40] [41]. The standardization of data collection methodologies implemented with WDT and the use of occupancy models to account for biases in detection helps reduce the noise inherent in opportunistic data collection. The results presented here represent the first use of occupancy models on opportunistic data and showcase the potential use of such data to make ecological and management inferences.

\subsection{Implications}

Understanding patterns of habitat use and distribution among differing social groups of humpback whales identifies areas where potential anthropogenic effects could impact these animals. The preference of mothers with calves for shallower waters and nearshore areas overlaps with areas that are frequently used for fishing, whalewatching, and other recreational activities. Furthering our understanding of habitat preference and use, in conjunction with continued long-term monitoring as presented here, is of critical importance to developing biologically relevant conservation initiatives and management plans. Minimizing disturbance to mother-calf pods will likely contribute to the continued recovery of the Hawaiian population segment following its recent delisting from the United States Endangered Species Act. This study region largely comprises the Hawaiian Islands Humpback Whale National Marine Sanctuary, which has some restrictions in place to manage this population of whales: a minimum approach distance by water and air and restrictions on certain types of high-speed vessels (parasailing and jet-skis) between December and April. A greater understanding of habitat preference by mother-calf pairs in this important breeding ground could lead to informed management practices, including but not limited to, timed area closures or speed restrictions in the areas and times when calves are more likely to be present.

\section{Acknowledgements}

We would like to thank the members and supporters of Pacific Whale Foundation for providing funding for this work. Special gratitude goes out to Greg Kaufman for initial development and conceptualization of Whale and Dolphin Tracker and opportunistic data collection. Additionally we extend thanks to Blake Moore and Morgan Wittmer, all captains and naturalists of PacWhale Eco-Adventures who contributed to data collection, and the research interns who helped with data processing. We would also like to thank Joe Breman and International Underwater Explorations Tech for working with Pacific Whale 
Foundation on development of the Whale \& Dolphin Tracker application.

\section{References}

[1] Mobley, J.M. and Herman, L.M. (1985) Transience of Social Affiliations among Humpback Whales (Megaptera novaeangliae) on Hawaiian Wintering Grounds. Canadian Journal of Zoology, 63, 762-774. https://doi.org/10.1139/z85-111

[2] Szabo, A. and Duffus, D. (2008) Mother-Offspring Association in the Humpback Whale, Megaptera novaeangliae: Following Behaviour in an Aquatic Mammal. Animal Behaviour, 75, 1085-1092. https://doi.org/10.1016/j.anbehav.2007.08.019

[3] National Marine Fisheries Service (2016) Monitoring Plan for Nine Distinct Population Segments of the Humpback Whale (Megaptera novaeangliae). National Marine Fisheries Service, Office of Protected Resources, Silver Spring, 19.

[4] Calambokidis, J., Falcone, E.A., Quinn, T.J., Burdin, A.M., Clapham, P.J., Ford, J.K.B., Gabriele, C.M., LeDuc, R., Mattila, D., Rojas-Bracho, L., Straley, J.M., Taylor, B.L., Urbán, J.R., Weller, D., Witteveen, B.H., Yamaguchi, M., Bendlin, A., Camacho, D., Flynn, K., Havron, A., Huggings, J., Maloney, N., Barlow, J. and Wade, P.R. (2008) SPLASH: Structure of Populations, Levels of Abundance and Status of Humpback Whales in the North Pacific. Unpublished Report Submitted by Cascadia Research Collective to USDOC, Seattle.

[5] Bettridge, S., Baker, C.S., Barlow, J., Clapham, P.J., Ford, M., Gouveia, D., Mattila, D.K., Pace III, R.M., Rosel, P.E., Silber, G.K. and Wade, P.R. (2015) Status Review of the Humpback Whale (Megaptera novaeangliae) under the Endangered Species Act. NOAA Technical Memorandum NMFS, NOAA-TM-NMFSSWFSC-540, US Department of Commerce, National Oceanic and Atmospheric Administration, National Marine Fisheries Service, Southwest Fisheries Science Center, California.

[6] Mobley, J.R., Bauer, G.B. and Herman, L.M. (1999) Changes over a Ten-Year Interval in the Distribution and Relative Abundance of Humpback Whales (Megaptera novaeangliae) Wintering in Hawaiian Waters. Aquatic Mammals, 25, 63-72.

[7] Mobley, J.M., Spitz, S., Grotefendt, R., Forestell, P., Frankel, A. and Bauer, G. (2001) Abundance of Humpback Whales in Hawaiian Waters: Results of 1993-2000 Aerial Surveys. Report to the Hawaiian Islands Humpback Whale National Marine Sanctuary, Kihei.

[8] Herman, L.M. and Antinoja, R.C. (1977) Humpback Whales in the Hawaiian Breeding Waters: Population and Pod Characteristics. The Scientific Reports of the Whales Research Institute, 29, 59-85.

[9] Smultea, M.A. (1994) Segregation by Humpback Whale (Megaptera novaeangliae) Cows with Calves in Coastal Habitat near the Island of Hawaii. Canadian Journal of Zoology, 72, 805-811. https://doi.org/10.1139/z94-109

[10] Ersts, P.J. and Rosenbaum, H.C. (2003) Habitat Preference Reflects Social Organization of Humpback Whales (Megaptera novaeangliae) on a Wintering Ground. Journal of Zoology, 260, 337-345. https://doi.org/10.1017/S0952836903003807

[11] Cerchio, S., Gabriele, C.M., Norris, T.F. and Herman, L.M. (1998) Movements of Humpback Whales between Kauai and Hawaii: Implications for Population Structure and Abundance Estimation in the Hawaiian Islands. Marine Ecology Progress Series, 175, 13-22. https://doi.org/10.3354/meps175013

[12] Craig, A.S. and Herman, L.M. (2000) Habitat Preferences of Female Humpback Whales Megaptera novaeangliae in the Hawaiian Islands Are Associated with Reproductive Status. Marine Ecology Progress Series, 193, 209-216. https://doi.org/10.3354/meps193209 
[13] Félix, F. and Haase, B. (1997) Spatial Distribution of Different Age Groups of Humpback Whales along the Ecuadorian Coast. European Research on Cetaceans, 11, 129-132.

[14] Martins, C.C.A., Morete, M.E., Coitinho, M.H.E., Freitas, A.C., Secchi, E.R. and Kinas, P.G. (2001) Aspects of Habitat Use Patterns of Humpback Whales in the Abrolhos Bank, Brazil, Breeding Ground. Memoirs of the Queensland Museum, 47, 563-570.

[15] Oviedo, L. and Solís, M. (2008) Underwater Topography Determines Critical Breeding Habitat for Humpback Whales near Osa Peninsula, Costa Rica: Implications for Marine Protected Areas. Revista de biologia tropical, 56, 591-602.

[16] Craig, A.S., Herman, L.M., Pack, A.A. and Waterman, J.O. (2014) Habitat Segregation by Female Humpback Whales in Hawaiian Waters: Avoidance of Males? Behaviour, 151, 613-631. https://doi.org/10.1163/1568539X-00003151

[17] Frankel, A.S. and Clark, C.W. (2002) ATOC and Other Factors Affecting the Distribution and Abundance of Humpback Whales (Megaptera novaeangliae) off the North Shore of Kauai. Marine Mammal Science, 18, 644-662.

https://doi.org/10.1111/j.1748-7692.2002.tb01064.x

[18] Cartwright, R., Gillespie, B., LaBonte, K., Mangold, T., Venema, A., Eden, K. and Sullivan, M. (2012) Between a Rock and a Hard Place: Habitat Selection in Female-Calf Humpback Whale (Megaptera novaeangliae) Pairs on the Hawaiian Breeding Grounds. PLoS ONE, 7, e38004. https://doi.org/10.1371/journal.pone.0038004

[19] MacKenzie, D.I., Nichols, J.D., Royle, J.A., Pollock, K.H., Bailey, L.L. and Hines, J.E. (2006) Occupancy Estimation and Modeling: Inferring Patterns and Dynamics of Species Occurrence. Elsevier Academic Press, Burlington.

[20] Martin, J., Chamaillé-Jammes, S., Nichols, J.D., Fritz, H., Hines, J.E., Fonnesbeck, C.J., MacKenzie, D.I. and Bailey, L.L. (2010) Simultaneous Modeling of Habitat Suitability, Occupancy, and Relative Abundance: African Elephants in Zimbabwe. Ecological Applications, 20, 1173-1182. https://doi.org/10.1890/09-0276.1

[21] Cove, M.V., Pardo Vargas, L.E., de la Cruz, J.C., Spínola, R.M., Jackson, V.L., Saénz, J.C. and Chassot, O. (2013) Factors Influencing the Occurrence of the Endangered Baird's Tapir Tapirus bairdii: Potential Flagship Species for a Costa Rican Biological Corridor. OryX, 48, 402-409. https://doi.org/10.1017/S0030605313000070

[22] Grigg, R., Grossman, E., Earle, S., Gittings, S., Lott, D. and McDonough, J. (2002) Drowned Reefs and Antecedent Karst Topography, Au'au Channel, SE Hawaiian Islands. Coral Reefs, 21, 73-82. https://doi.org/10.1007/s00338-001-0203-8

[23] Currie, J.J., Stack, S.H., McCordic, J.A. and Kaufman, G.D. (2015) Whale and Dolphin Tracker: An Application for Data Collection on Platforms of Opportunity. Document SC/66b/WW08 Presented to the IWC Scientific Committee, 11 p.

[24] MacKenzie, D.I. (2006) Modeling the Probability of Resource Use: The Effect of, and Dealing with, Detecting a Species Imperfectly. The Journal of Wildlife Management, 70, 367-374. https://doi.org/10.2193/0022-541X(2006)70[367:MTPORU]2.0.CO;2

[25] Dwyer, S.L. (2014) Spatial Ecology and Conservation of Cetaceans using the Hauraki Gulf, New Zealand. Unpublished PhD Thesis, Massey University, Auckland, 275 p.

[26] HMRG (2017) The School of Ocean and Earth Science and Technology. The University of Hawai'i, Manoa. http://www.soest.hawaii.edu/hmrg/multibeam/bathymetry.php

[27] ESRI (2017) ArcGIS Desktop: Release 10. Environmental Systems Research Insti- 
tute, Redlands.

[28] Jenness, J.S. (2004) Calculating Landscape Surface Area from Digital Elevation Models. Wildlife Society Bulletin, 32, 829-839. https://doi.org/10.2193/0091-7648(2004)032[0829:CLSAFD]2.0.CO;2

[29] R Core Team (2017) R: A Language and Environment for Statistical Computing. R Foundation for Statistical Computing, Vienna. https://www.R-project.org/

[30] Gonzalez-Suarez, M., Gómez, A. and Revilla, E. (2013) Which Intrinsic Traits Predict Vulnerability to Extinction Depends on the Actual Threatening Processes. Ecosphere, 4, 1-16. https://doi.org/10.1890/ES12-00380.1

[31] Fiske, I. and Chandler, R. (2011) Unmarked: An R Package for Fitting Hierarchical Models of Wildlife Occurrence and Abundance. Journal of Statistical Software, 43, 1-23. https://doi.org/10.18637/jss.v043.i10

[32] MacKenzie, D.I., Nichols, J.D., Hines, J.E., Knutson, M.G. and Franklin, A.B. (2003) Estimating Site Occupancy, Colonization, and Local Extinction When a Species Is Detected Imperfectly. Ecology, 84, 2200-2207. https://doi.org/10.1890/02-3090

[33] Burnham, K.P. and Anderson, D.R. (2002) Model Selection and Multimodel Inference: A Practical Information-Theoretic Approach. Springer-Verlag, New York.

[34] MacKenzie, D.I. and Bailey, L.L. (2004) Assessing the Fit of Site-Occupancy Models. Journal of Agricultural, Biological, and Environmental Statistics, 9, 300-318. https://doi.org/10.1198/108571104X3361

[35] Whitehead, H. and Moore, M.J. (1982) Distribution and Movements of West Indian Humpback Whales in Winter. Canadian Journal of Zoology, 60, 2203-2211. https://doi.org/10.1139/z82-282

[36] Mattila, D.K. and Clapham, P.J. (1989) Humpback Whales, Megaptera novaeangliae, and Other Cetaceans on Virgin Bank and in the Northern Leeward Islands, 1985 and 1986. Canadian Journal of Zoology, 67, 2201-2211. https://doi.org/10.1139/z89-311

[37] Chavanne, C., Flament, P., Lumpkin, R., Dousset, B. and Bentamy, A. (2002) Scatterometer Observations of Wind Variations Induced by Oceanic Islands: Implications for Wind-Driven Ocean Circulation. Canadian Journal of Remote Sensing, 28, 466-474. https://doi.org/10.5589/m02-047

[38] Stopa, J.E., Filipot, J.F., Li, N., Cheung, K.F., Chen, Y.L. and Vega, L. (2013) Wave Energy Resources along the Hawaiian Island Chain. Renewable Energy, 55, 305-321. https://doi.org/10.1016/j.renene.2012.12.030

[39] PacIOOS (2018) Pacific Islands Ocean Observing System. http://www.pacioos.org

[40] Herman, L.M., Forestell, P.H. and Antinoja, R.C. (1980) The 1976/77 Migration of Humpback Whales into Hawaiian Waters: Composite Description. Rep No. MMC-77/19, Marine Mammal Commission, Washington DC.

[41] Glockner-Ferrari, D.A. and Ferrari, M.J. (1985) Individual Identification, Behavior, Reproduction, and Distribution of Humpback Whales, Megaptera novaeangliae, in Hawaii. US Marine Mammal Commission.

[42] Chittleborough, R.G. (1965) Dynamics of Two Populations of the Humpback Whale, Megaptera novaeangliae (Borowski). Australian Journal of Marine and Freshwater Research, 16, 33-128. https://doi.org/10.1071/MF9650033

[43] Baker, C.S. and Herman, L.M. (1981) Migration and Local Movement of Humpback Whales (Megaptera novaeangliae) through Hawaiian Waters. Canadian Journal of Zoology, 59, 460-469. https://doi.org/10.1139/z81-067 